\section{Patients with a future diagnosis of diabetes have higher drug use and costs: an analysis of community pharmacy data}

\author{
Sandra De Coster,' Gert Laekeman,' \\ Jan Lenie, ${ }^{2}$ Véronique Hayen, ${ }^{2}$ \\ Steven Simoens'
}

'Research Centre for Pharmaceutical Care and Pharmaco-economics, Katholieke

Universiteit Leuven, Leuven, Belgium

${ }^{2}$ Royal Pharmaceutical Society of

Limburg, Hasselt, Belgium

\section{Abstract}

This study explores whether patients with Type 2 diabetes mellitus have higher drug use as compared to patients without diabetes over a time period prior to and after diagnosis of diabetes. A case-control study compared drug use of patients with a future diagnosis of diabetes (cases) with patients without a diagnosis (controls) based on community pharmacy records. Cases had used oral hypoglycaemic drugs during 2006. A repeated measures analysis calculated the mean number of packages and costs of drugs in cases during the two years prior to diagnosis and the first year following diagnosis and in control patients during three years. Volume of drug use was expressed as the number of packages consumed by a patient. Drug costs were based on the public price. Our dataset covered 2,697 patients (899 cases and 1,798 control patients). The mean annual number of packages and costs of drugs increased over time for cases and control patients $(\mathrm{P}<0.001)$. In patients with a future diagnosis of diabetes, the growth in drug use and costs over time was more pronounced than in control patients $(\mathrm{P}<0.001)$. Higher drug use and costs were mainly observed for cardiovascular drugs, antidepressant and antipsychotic drugs, and drugs related to gastric acid disorders. Patients with a future diagnosis of diabetes have higher drug use and costs prior to diagnosis than control patients. Drug use could be an indicator to trigger active monitoring for Type 2 diabetes mellitus.

\section{Introduction}

Type 2 diabetes mellitus is associated with significant morbidity, impaired quality of life, mortality; and is a primary driver of healthcare costs and lost productivity. ${ }^{1,2}$ It is estimated that nearly 170 million people had diabetes worldwide in 2000 (of whom $90-95 \%$ suffered from Type 2 diabetes) and this number is expected to increase to 365 million people in $2030 .^{3}$ Healthcare costs associated with diabetes amounted to $11.6 \%$ of public healthcare expenditure in 2010 worldwide. ${ }^{4}$ In the United States, approximately $\$ 116$ billion was spent on the treatment of diabetes and its complications in 2007.5

This clinical and economic burden is not limited to patients who have diabetes, but may already be imposed on patients prior to diagnosis (so-called pre-diabetes). Indeed, patients with a future diagnosis of diabetes have a higher probability of endocrine, metabolic, nutritional or cardiovascular disorders as compared to control patients. ${ }^{6-8}$ Multiple studies have supported the effectiveness of lifestyle interventions and metformin therapy for patients suffering from impaired fasting glucose and/or impaired glucose tolerance, conditions where blood glucose levels are higher than normal but not high enough to be classified as diabetes. ${ }^{9-12}$

This underlines the importance of screening for diabetes and of the provision of health care prior to diagnosis of diabetes. The benefits of screening originate from earlier diagnosis and treatment of diabetes, thereby postponing or preventing progression to diabetes complications. The few studies that have examined the cost-effectiveness of screening for Type 2 diabetes have focused on patients who present themselves to physicians and who are screened during an already scheduled physician visit. ${ }^{13-15}$ There may be a role for pharmacists to contribute to targeted screening by informing people about Type 2 diabetes and encouraging high-risk people to visit a physician to be screened. ${ }^{16}$ Another way in which community pharmacy may aid screening for diabetes is the analysis of patient drug use and costs. Drug use might reveal endocrinological changes and help to identify indicators for active monitoring for Type 2 diabetes. Drug use is also being used in risk algorithms to predict the risk of developing Type 2 diabetes, such as anti-hypertensives and steroids in the QDScore. ${ }^{17}$ Such factual evidence can be used by health authorities as an incentive to promote preventive measures to lower the incidence of diabetes and to avoid additional costs related to drugs.

The aim of this study is to assess whether patients with Type 2 diabetes mellitus have higher drug use and costs as compared to patients without diabetes over a time period prior to and after diagnosis of diabetes in a community-based cohort of individuals. This study will add specific drugs to a checklist to select high-risk patients and enhance the yield of preventing or postponing the onset of Type 2 diabetes mellitus.
Correspondence: Steven Simoens, Research Centre for Pharmaceutical Care and Pharmacoeconomics, Katholieke Universiteit Leuven. Onderwijs en Navorsing 2, Herestraat 49, P.O. Box 521, 3000 Leuven, Belgium.

Tel. +32.16 .323465 - Fax: +32.16 .323468 .

E-mail: steven.simoens@pharm.kuleuven.be

Acknowledgements: this study received no funding. The authors would like to express their gratitude to the Royal Pharmaceutical Society of Limburg for permitting access to drug reimbursement data.

Key words: community pharmacy, diagnosis, drug use, drug costs, type 2 diabetes mellitus.

Conflict of interest: the authors report no conflicts of interest.

Authors' contributions: JL,VH, study design, data extraction, manuscript review; SDC, study design, data analysis; SDC, SS, study design, manuscript writing, manuscript review; GL, study design and supervision, manuscript review.

Received for publication: 1 April 2011

Revision received:

Accepted for publication:

This work is licensed under a Creative Commons Attribution 3.0 License (by-nc 3.0).

(C) Copyright De Coster et al., 2011

Licensee PAGEPress, Italy

Endocrinology Studies 2011; 1:e6

doi:10.4081/es.2011.e6

\section{Design and Methods}

\section{Data sources}

In Belgium, community pharmacies generally transfer data on reimbursed drugs to the reimbursement department of a regional pharmaceutical society. The pharmaceutical society checks these data and then forwards them to the various health insurance funds and ultimately to the National Institute for Health and Disability Insurance, the Belgian third-party payer, for reimbursement purposes. Our study drew on patient-level data on reimbursed drugs transmitted by 275 community pharmacies in the Belgian province of Limburg to the the Royal Pharmaceutical Society of Limburg (Koninklijk Limburgs Apothekers Verbond). In order to comply with privacy rules, data were anonymised by the Royal Pharmaceutical Federation of Limburg. Data from January 2004 to December 2007 were available for this study.

\section{Study participants}

The study enrolled patients with a future diagnosis of diabetes (experimental patients) and patients without a future diagnosis (con- 
trol patients). A subject was identified as an experimental patient if (s)he was a new user of oral hypoglycaemic drugs such as metformin, sulfonylurea, glinides and glitazones between $1^{\text {st }}$ January 2006 and $31^{\text {st }}$ December 2006 . The study enrolled patients probably suffering from Type 2 diabetes mellitus by excluding patients diagnosed before 29 years of age or patients taking insulin. Control patients had not used insulin or oral hypoglycaemic drugs during the study period.

For each experimental patient, two control patients were randomly selected from all patients who had never used insulin or oral hypoglycaemic drugs. The community pharmacy database contained data on age and gender of patients (but unfortunately not on other patient characteristics or clinical indicators) and provided a complete overview of the medicines used. Therefore, experimental and control patients were matched in terms of fiveyear age bands, gender and quarter of index date (referring to the date of the first oral hypoglycaemic drug in the experimental group or the analogue date in the control group). We ensured that every control patient had a twoyear drug record prior to and a one-year drug record following the index date of the matched experimental patient. Therefore, inclusion was restricted to those patients who used at least one reimbursed drug every year throughout the entire study period (2004-2007). In this study, year-1 and year-2 do not refer to calendar years but to the first and the second 365-day period preceding the first oral hypoglycaemic drug, respectively. year-1 refers to the first 365 day period following the first oral hypoglycaemic drug.

\section{Study design}

A mixed study design was used consisting of a repeated measures analysis nested in a casecontrol analysis (Figure 1). The repeated measures analysis explored the mean volume of drug use and costs in experimental patients during the two years prior to diagnosis and the first year following diagnosis and in control patients during the three consecutive years.

The case-control design allowed us to eliminate changes that would have occurred in the absence of diabetes and provided a further control against secular changes in prices and treatment guidelines over time. Furthermore, to compensate for possible seasonal changes in drug use and costs, experimental and control patients were matched by quarter of index date.

\section{Drug use and costs}

For each patient, drug use was registered according to the ATC (Anatomical-Therapeutic-Chemical) classification system, which is based on the organ or system on which drugs mainly act and in subcategories

\begin{tabular}{|c|c|c|c|c|}
\hline \multirow{2}{*}{$\begin{array}{l}\text { Case-control } \\
\text { analysis }\end{array}$} & \multicolumn{4}{|c|}{ Repeated measures analysis } \\
\hline & Year-2 & Year-1 & $\begin{array}{c}\text { Index year } \\
2006\end{array}$ & Year+1 \\
\hline Experimental group & $\begin{array}{l}\text { Drug } \\
\text { use and } \\
\text { costs } \\
\end{array}$ & $\begin{array}{l}\text { Drug } \\
\text { use and } \\
\text { costs }\end{array}$ & $\begin{array}{c}\text { Oral } \\
\text { hypoglycaemic } \\
\text { drug }\end{array}$ & $\begin{array}{l}\text { Drug } \\
\text { use and } \\
\text { costs }\end{array}$ \\
\hline Control group & $\begin{array}{l}\text { Drug } \\
\text { use and } \\
\text { costs }\end{array}$ & $\begin{array}{l}\text { Drug } \\
\text { use and } \\
\text { costs }\end{array}$ & $\begin{array}{c}\text { No oral } \\
\text { hypoglycaemic } \\
\text { drug }\end{array}$ & $\begin{array}{l}\text { Drug } \\
\text { use and } \\
\text { costs }\end{array}$ \\
\hline
\end{tabular}

Figure 1. Study design.

according to substance class. Analyses were performed for all ATC codes together and per ATC group. ATC groups were selected based on possible co-morbidities associated with diabetes as described in the literature. ${ }^{18-25}$ Volume of drug use was expressed as the number of packages consumed by the individual patient. Costs of drug were reported as the public price (i.e. third-party payer reimbursement and possible patient co-payment) at delivery date and were expressed in Euro. Costs were not standardized to a reference year as drug prices remained relatively constant during the study period. No data were available on over-thecounter drugs or drugs that are not reimbursed by the Belgian third-party payer.

\section{Statistical analysis}

A repeated measures ANOVA was performed to explore mean annual drug use and costs in patients with and without a future diagnosis of diabetes over the three-year study period. To reduce positive skew and inequality of variances, a logarithmic transformation was applied to the original dataset. Additionally, pvalues were corrected according to Greenhouse-Geisser. For each separate year, use and costs of drug between experimental and con-

Table 1. Demographic characteristics of patients.

\begin{tabular}{lcc} 
& Experimental group & Control group \\
& 899 & 1,798 \\
Age, number of patients* & & \\
\hline Mean age & 57 & 57 \\
29-38 years & $28(3 \%)$ & $56(3 \%)$ \\
39-48 years & $118(13 \%)$ & $236(13 \%)$ \\
49-58 years & $336(37 \%)$ & $672(37 \%)$ \\
59-68 years & $417(46 \%)$ & $834(46 \%)$ \\
Gender, number of patients (\%)* & & \\
\hline Men & $456(51 \%)$ & $912(51 \%)$ \\
$\quad$ Women & $443(49 \%)$ & $886(49 \%)$ \\
Quarter of index date & & 606 \\
\hline Jan '06 - March '06 & 303 & 182 \\
April '06 - June '06 & 246 & 492 \\
July '06 - Sept '06 & 168 & 336 \\
Oct '06 - Dec '06 & 364 & \\
\hline
\end{tabular}

*Experimental and control patients were matched in terms of five-year age bands, gender and quarter of index date. trol patients were compared using the MannWhitney U-test. Within the experimental group, drug use and costs were contrasted prior to and following diagnosis of diabetes using a Wilcoxon test. Data were analysed in SPSS 16.0 for Windows.

\section{Results}

Our dataset covered 2,697 patients, consisting of 899 experimental patients and 1,798 control patients. Mean age at index date was 57 years. Fifty-one percent of patients were male. The demographic characteristics of the patient sample are described in Table 1.

Mean total number of packages and costs of drugs in experimental patients and control patients over three years is presented in Figure 2. There was a significant effect of time, indicating that the mean annual number of packages and costs of drugs increased over the three observed years for experimental patients and for control patients $(\mathrm{P}<0.001)$. Additionally, a significant interaction effect was observed between time and study group. 
Table 2. Number of packages and costs of drugs in experimental and control patients by study year.

\begin{tabular}{|c|c|c|c|c|c|c|}
\hline \multirow[t]{2}{*}{ Year } & \multicolumn{3}{|c|}{ Number of drug packages, mean (range) } & \multicolumn{3}{|c|}{ Drug costs in Euro, mean (range) } \\
\hline & Experimental group & Control group & p-value & Experimental group & Control group & p-value \\
\hline \multicolumn{7}{|c|}{ All medication } \\
\hline-2 & $15.14(0-148)$ & $8.38(0-136)$ & $<0.001$ & $437.64(0.00-4407.18)$ & $239.49(0.00-3346.62)$ & $<0.001$ \\
\hline-1 & $16.16(0-156)$ & $9.90(0-165)$ & $<0.001$ & $464.00(0.00-5130.01)$ & $274.87(0.00-3310.02)$ & $<0.001$ \\
\hline+1 & $20.43(0-140)$ & $10.50(0-153)$ & $<0.001$ & $598.51(0.00-4064.66)$ & $285.06(0.00-3493.79)$ & $<0.001$ \\
\hline \multicolumn{7}{|c|}{ A02 : drugs for acid related disorders } \\
\hline-2 & $0.75(0-25)$ & $0.54(0-16)$ & 0.005 & $28.66(0.00-962.42)$ & $21.82(0.00-790.78)$ & 0.006 \\
\hline-1 & $0.82(0-20)$ & $0.59(0-17)$ & 0.023 & $29.61(0.00-728.93)$ & $21.70(0.00-747.88)$ & 0.035 \\
\hline+1 & $1.01(0-19)$ & $0.64(0-18)$ & $<0.001$ & $31.19(0.00-764.54)$ & $20.35(0.00-816.28)$ & $<0.001$ \\
\hline \multicolumn{7}{|c|}{ A07E : intestinal anti-inflammatory agents } \\
\hline-2 & $0.05(0-12)$ & $0.02(0-7)$ & 0.382 & $2.90(0.00-786.96)$ & $1.70(0.00-753.96)$ & 0.382 \\
\hline-1 & $0.05(0-18)$ & $0.05(0-19)$ & 0.805 & $2.89(0.00-826.84)$ & $3.10(0.00-1481.26)$ & 0.805 \\
\hline+1 & $0.05(0-11)$ & $0.04(0-17)$ & 0.899 & $3.84(0.00-726.00)$ & $2.13(0.00-679.77)$ & 0.897 \\
\hline \multicolumn{7}{|c|}{ B01 : Antithrombotic agents } \\
\hline-2 & $0.64(0-29)$ & $0.32(0-29)$ & $<0.001$ & $24.85(0.00-1714.90)$ & $12.99(0.00-830.36)$ & $<0.001$ \\
\hline-1 & $0.69(0-29)$ & $0.43(0-23)$ & 0.026 & $26.70(0.00-1677.49)$ & $18.42(0.00-1189.50)$ & 0.033 \\
\hline+1 & $1.19(0-36)$ & $0.49(0-26)$ & $<0.001$ & $48.85(0.00-2032.57)$ & $20.75(0.00-895.49)$ & $<0.001$ \\
\hline \multicolumn{7}{|c|}{ C01 : Cardiac therapy } \\
\hline-2 & $0.56(0-19)$ & $0.20(0-23)$ & $<0.001$ & $16.02(0.00-649.71)$ & $5.95(0.00-645.69)$ & $<0.001$ \\
\hline-1 & $0.56(0-17)$ & $0.23(0-21)$ & $<0.001$ & $16.65(0.00-643.54)$ & $7.06(0.00-705.63)$ & $<0.001$ \\
\hline+1 & $0.67(0-20)$ & $0.22(0-21)$ & $<0.001$ & $19.13(0.00-790.68)$ & $6.17(0.00-613.22)$ & $<0.001$ \\
\hline \multicolumn{7}{|c|}{ C02 : Antihypertensives } \\
\hline-2 & $0.18(0-16)$ & $0.05(0-17)$ & $<0.001$ & $3.16(0.00-324.80)$ & $0.84(0.00-283.51)$ & $<0.001$ \\
\hline-1 & $0.14(0-13)$ & $0.05(0-14)$ & $<0.001$ & $2.55(0.00-301.60)$ & $0.74(0.00-301.60)$ & $<0.001$ \\
\hline+1 & $0.15(0-11)$ & $0.04(0-17)$ & $<0.001$ & $2.64(0.00-260.04)$ & $0.73(0.00-295.62)$ & $<0.001$ \\
\hline \multicolumn{7}{|c|}{ C03 : Diuretics } \\
\hline-2 & $0.91(0-22)$ & $0.22(0-24)$ & $<0.001$ & $11.76(0.00-392.47)$ & $2.76(0.00-244.16)$ & $<0.001$ \\
\hline-1 & $1.03(0-31)$ & $0.30(0-23)$ & $<0.001$ & $12.36(0.00-445.52)$ & $3.51(0.00-252.64)$ & $<0.001$ \\
\hline+1 & $1.13(0-30)$ & $0.32(0-18)$ & $<0.001$ & $13.24(0.00-412.16)$ & $3.46(0.00-224.64)$ & $<0.001$ \\
\hline \multicolumn{7}{|c|}{ C07 : Beta blocking agents } \\
\hline-2 & $2.51(0-24)$ & $0.95(0-16)$ & $<0.001$ & $40.90(0.00-379.85)$ & $15.13(0.00-305.76)$ & $<0.001$ \\
\hline-1 & $2.83(0-40)$ & $1.21(0-18)$ & $<0.001$ & $42.83(0.00-651.60)$ & $17.90(0.00-285.98)$ & $<0.001$ \\
\hline+1 & $3.39(0-38)$ & $1.33(0-21)$ & $<0.001$ & $47.26(0.00-619.02)$ & $18.29(0.00-305.76)$ & $<0.001$ \\
\hline \multicolumn{7}{|c|}{ C08: Calcium channel blockers } \\
\hline-2 & $0.74(0-16)$ & $0.36(0-20)$ & $<0.001$ & $19.21(0.00-408.73)$ & $8.53(0.00-461.00)$ & $<0.001$ \\
\hline-1 & $0.72(0-17)$ & $0.40(0-14)$ & $<0.001$ & $17.30(0.00-418.03)$ & $8.66(0.00-299.65)$ & $<0.001$ \\
\hline+1 & $0.97(0-15)$ & $0.45(0-15)$ & $<0.001$ & $22.26(0.00-443.60)$ & $9.14(0.00-379.51)$ & $<0.001$ \\
\hline \multicolumn{7}{|c|}{$\mathrm{C} 09$ : Agents acting on the renin-angiotensin system } \\
\hline-2 & $1.31(0-25)$ & $0.61(0-31)$ & $<0.001$ & $50.10(0.00-822.12)$ & $26.83(0.00-1021.98)$ & $<0.001$ \\
\hline-1 & $1.43(0-26)$ & $0.76(0-20)$ & $<0.001$ & $54.17(0.00-789.67)$ & $30.50(0.00-620.80)$ & $<0.001$ \\
\hline+1 & $2.32(0-21)$ & $0.89(0-14)$ & $<0.001$ & $80.27(0.00-822.12)$ & $62.61(0.00-1456.96)$ & $<0.001$ \\
\hline \multicolumn{7}{|c|}{ C10 : Lipid modifying agents } \\
\hline-2 & $1.01(0-13)$ & $0.54(0-12)$ & $<0.001$ & $89.73(0.00-1616.80)$ & $46.03(0.00-960.64)$ & $<0.001$ \\
\hline-1 & $1.23(0-12)$ & $0.76(0-12)$ & $<0.001$ & $94.65(0.00-1505.74)$ & $56.63(0.00-1088.14)$ & $<0.001$ \\
\hline+1 & $2.37(0-12)$ & $0.89(0-14)$ & $<0.001$ & $162.34(0.00-1614.40)$ & $62.61(0.00-1456.96)$ & $<0.001$ \\
\hline \multicolumn{7}{|c|}{ H02 : Corticosteroids for systemic use } \\
\hline-2 & $0.20(0-14)$ & $0.54(0-12)$ & 0.091 & $89.73(0.00-1616.80)$ & $46.03(0.00-960.64)$ & 0.087 \\
\hline-1 & $0.24(0-13)$ & $0.76(0-12)$ & 0.478 & $94.65(0.00-1505.74)$ & $56.63(0.00-1088.14)$ & 0.551 \\
\hline+1 & $0.27(0-15)$ & $0.89(0-14)$ & 0.566 & $162.34(0.00-1614.40)$ & $62.61(0.00-1456.96)$ & 0.496 \\
\hline \multicolumn{7}{|c|}{ J01 : Antibacterials for systemic use } \\
\hline-2 & $1.27(0-15)$ & $1.01(0-46)$ & $<0.001$ & $26.31(0.00-388.52)$ & $20.35(0.00-903.24)$ & $<0.001$ \\
\hline-1 & $1.20(0-13)$ & $1.13(0-42)$ & 0.317 & $23.77(0.00-323.64)$ & $21.43(0.00-820.26)$ & 0.196 \\
\hline+1 & $1.33(0-25)$ & $1.05(0-41)$ & 0.002 & $24.76(0.00-581.77)$ & $19.56(0.00-598.91)$ & 0.001 \\
\hline \multicolumn{7}{|c|}{ J02 : Antimycotics for systemic use } \\
\hline-2 & $0.09(0-10)$ & $0.08(0-8)$ & 0.615 & $4.64(0.00-414.69)$ & $1.99(0.00-490.77)$ & 0.640 \\
\hline-1 & $0.12(0-4)$ & $0.10(0-14)$ & 0.018 & $6.75(0.00-452.94)$ & $4.99(0.00-806.01)$ & 0.018 \\
\hline+1 & $0.10(0-8)$ & $0.08(0-4)$ & 0.143 & $5.29(0.00-734.88)$ & $3.87(0.00-423.29)$ & 0.225 \\
\hline
\end{tabular}


Number of packages of drug use

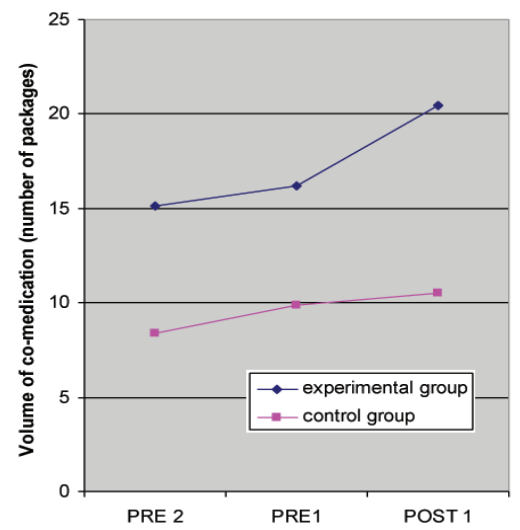

Costs of drug use (in Euro)

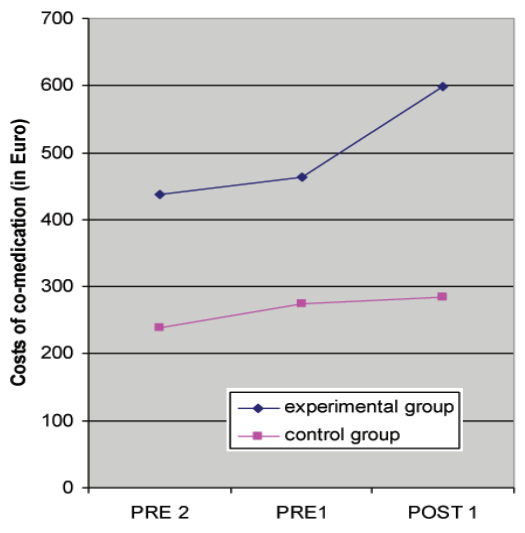

vs. 1.43). A higher use was also reported for calcium channel blockers ( 0.97 vs. 0.72 ) and beta blocking agents (3.39 vs. 2.83). With respect to drugs for acid related disorders, a significant increase in the mean total number of packages was observed following diagnosis (1.01 vs. 0.82 ). However, this was not the case for mean annual costs.

\section{Discussion}

This study compared the use and costs of drugs in patients with a future diagnosis of Type 2 diabetes mellitus and in patients without a future diagnosis. This observational, retrospective study drew on drug use data that reflect actual clinical practice in the community.

Although use and costs of drugs increased over time for all patients, this growth was more pronounced for patients with a future diagnosis of diabetes than for control patients. Patients with a future diagnosis of diabetes appear to have higher drug use and costs, not only during the first year following diagnosis but also during the two years preceding diagnosis. This effect was mainly observed for cardiovascular drugs, antidepressant and antipsychotic drugs, and drugs related to gastric acid disorders. This study has demonstrated that patients use more medication prior to becoming diabetic as compared to controls, free from diabetes during the whole study period.

The reader should be aware of the characteristics of our study sample. Patients suffering from Type 2 diabetes mellitus were identified by their use of oral hypoglycaemic drugs such as metformin, sulfonylurea, glinides and glitazones. However, metformin may also be prescribed for patients with polycystic ovary syndrome, but this is likely to involve a small number of patients. ${ }^{7}$ Also, our sample of cases with a future diagnosis of diabetes may have included patients with undiagnosed diabetes, patients with pre-diabetes, and patients with gestational diabetes. Such patients have impaired fasting glucose and/or impaired glucose tolerance, conditions where blood glucose levels are higher than normal. ${ }^{27}$ Previous research has indicated that general practitioners pay little attention to the clinical significance of impaired glucose tolerance and, thus, may fail to diagnose such patients. ${ }^{28}$

Since the sample enrolled patients who used at least one prescription drug per year, the control group may have higher morbidity than the Belgian population that does not take drugs. As higher drug use and costs were observed when comparing patients with a future diagnosis of diabetes with a control group of patients who take drugs, we would expect this result to be corroborated when comparing patients with a future diagnosis of diabetes with a healthy 
control group. Finally, the community pharmacy database contained little information about demographic characteristics of patients. Our study found that the association between drug use and the future diagnosis of diabetes did not vary between men and women. Future studies need to explore whether there is an interaction with other demographic or socioeconomic variables.

There is a need for more research into the causes of the association between the future diagnosis of diabetes and drug use. For instance, the higher use of beta-blocking agents by patients with a future diagnosis of diabetes may derive from the fact that betablocking agents can cause an increase in fasting blood glucose and impaired glucose tolerance. ${ }^{27}$ Also, future studies may wish to replicate this analysis for specific subgroups of patients prior to, or already suffering from Type 2 diabetes mellitus, such as for example diet-controlled diabetes. Furthermore, the question can be asked what difference between experimental and control patients must exist to start active monitoring for diabetes? This study did not intend to specify the size of the difference between experimental and control patients that would trigger active monitoring for Type 2 diabetes mellitus. Instead, it served to identify indicators for active monitoring that could be derived from community pharmacy databases.

In conclusion, patients with a future diagnosis of diabetes have higher drug use and costs prior to diagnosis than control patients. The study points to the potential role for community pharmacists to follow up drug indicators for active monitoring of diabetes and eventually to encourage high-risk people to visit a physician to be screened.

\section{References}

1. Egedeand LE, Simpson K. Epidemiology, treatment and costs of depression in adults with Type 2 diabetes. Expert Rev Pharmacoecon Outcomes Res 2003;3:25162 .

2. Engelgau MM, Geiss LS, Saaddine JB, et al. The evolving diabetes burden in the United States. Ann Intern Med 2004;140: 945-50.

3. Wild S, Roglic G, Green A, et al. Global prevalence of diabetes: estimates for the year 2000 and projections for 2030 . Diabetes Care 2004;27:1047-53.

4. Brito-Sanfiel M, ago-Cabezudo J, Calderon A. Economic impact of hypoglycemia on healthcare in Spain. Expert Rev Pharmacoecon Outcomes Res 2010;10:649-60.

5. Driver VR, Fabbi M, Lavery LA, Gibbons G. The costs of diabetic foot: the economic case for the limb salvage team. J Vasc Surg 2010;52:17S-22S.

6. D'Agostino RB Jr, Hamman RF, Karter AJ, et al. Cardiovascular disease risk factors predict the development of type 2 diabetes: the insulin resistance atherosclerosis study. Diabetes Care 2004;27:2234-40.

7. Gulliford MC, Charlton J, Latinovic R. Increased utilization of primary care 5 years before diagnosis of type 2 diabetes: a matched cohort study. Diabetes Care 2005;28:47-52.

8. Nichols GA, Glauber HS, Brown JB. Type 2 diabetes: incremental medical care costs during the 8 years preceding diagnosis. Diabetes Care 2000;23:1654-9.

9. Lindstrom J, Ilanne-Parikka P, Peltonen M. Sustained reduction in the incidence of type 2 diabetes by lifestyle intervention: follow-up of the Finnish Diabetes Prevention Study. Lancet 2006;368:1673-9.

10. Ratner R, Goldberg R, Haffner S, et al. Impact of intensive lifestyle and metformin therapy on cardiovascular disease risk factors in the diabetes prevention program. Diabetes Care 2005;28:888-94.

11. Tuomilehto J, Lindstrom J, Eriksson JG, et al. Prevention of type 2 diabetes mellitus by changes in lifestyle among subjects with impaired glucose tolerance. N Engl J Med 2001;344:1343-50.

12. Herman WH. The economics of diabetes prevention. Med Clin North Am 2011;95: 373-84.

13. CDC Diabetes Cost-effectiveness Study Group. The cost-effectiveness of screening for type 2 diabetes. JAMA 1998;280:175763.

14. Chen TH, Yen MF, Tung TH. A computer simulation model for cost-effectiveness analysis of mass screening for Type 2 diabetes mellitus. Diabetes Res Clin Pract 2001;54:S37-S42.

15. Hoerger TJ, Harris R, Hicks KA, et al. Screening for type 2 diabetes mellitus: a cost-effectiveness analysis. Ann Intern
Med 2004;140:689-99.

16. Simoens S, Foulon E, Dethier M, et al. Promoting targeted screening for Type 2 diabetes mellitus: the contribution of community pharmacists. Diabet Med 2005;22: 812-3.

17. Collins GS, Altman DG. External validation of $\mathrm{QDSCORE}((\mathrm{R}))$ for predicting the 10 year risk of developing Type 2 diabetes. Diabet Med 2011;28:599-607.

18. Brunton S. Beyond glycemic control: treating the entire type 2 diabetes disorder. Postgrad Med 2009;121:68-81.

19. Campbell R. Type 2 diabetes: where we are today: an overview of disease burden, current treatments, and treatment strategies. J Am Pharmaceutical Assoc 2009;49:S3-S9.

20. Choy CK, Rodgers JE, Nappi JM, Haines ST. Type 2 diabetes mellitus and heart failure. Pharmacotherapy 2008;28:170-92.

21. Goldberg RB. Cytokine and cytokine-like inflammation markers, endothelial dysfunction, and imbalanced coagulation in development of diabetes and its complications. J Clin Endocrinol Metab 2009;94: 3171-82.

22. Ma J, Rayner CK, Jones KL, Horowitz M. Diabetic gastroparesis: diagnosis and management. Drugs 2009;69:971-86.

23. Mezuk B, Eaton WW, Albrecht S, Golden SH. Depression and type 2 diabetes over the lifespan: a meta-analysis. Diabetes Care 2008;31:2383-90.

24. Spark RF. Testosterone, diabetes mellitus, and the metabolic syndrome. Curr Urol Rep 2007;8:467-71.

25. Tiengo A, Fadini GP, Avogaro A. The metabolic syndrome, diabetes and lung dysfunction. Diabetes Metab 2008;34:447-54.

26. National Institute for Health and Disability Insurance. Drug indicators. 2010. 28-42010. Ref Type: Internet Communication

27. Suter PM, Vetter W. Metabolic effects of antihypertensive drugs. J Hypertens Suppl 1995;13:S11-7.

28. Wylie G, Hungin AP, Neely J. Impaired glucose tolerance: qualitative and quantitative study of general practitioners' knowledge and perceptions. BMJ 2002;324:1190. 